\title{
Allele-specific transcriptional elongation regulates monoallelic expression of the IGF2BP1 gene
}

Brandon J Thomas ${ }^{1}$, Eric D Rubio ${ }^{1}$, Niklas Krumm², Pilib Ó Broin ${ }^{3,4}$, Karol Bomsztyk ${ }^{5}$, Piri Welcsh ${ }^{6}$, John M Greally ${ }^{7,8}$, Aaron A Golden ${ }^{7}$ and Anton Krumm ${ }^{1,9^{*}}$

\begin{abstract}
Background: Random monoallelic expression contributes to phenotypic variation of cells and organisms. However, the epigenetic mechanisms by which individual alleles are randomly selected for expression are not known. Taking cues from chromatin signatures at imprinted gene loci such as the insulin-like growth factor 2 gene 2 (IGF2), we evaluated the contribution of CTCF, a zinc finger protein required for parent-of-origin-specific expression of the IGF2 gene, as well as a role for allele-specific association with DNA methylation, histone modification and RNA polymerase II.
\end{abstract}

Results: Using array-based chromatin immunoprecipitation, we identified 293 genomic loci that are associated with both CTCF and histone $\mathrm{H} 3$ trimethylated at lysine 9 (H3K9me3). A comparison of their genomic positions with those of previously published monoallelically expressed genes revealed no significant overlap between allelespecifically expressed genes and colocalized CTCF/H3K9me3. To analyze the contributions of CTCF and H3K9me3 to gene regulation in more detail, we focused on the monoallelically expressed IGF2BPI gene. In vitro binding assays using the CTCF target motif at the IGF2BP1 gene, as well as allele-specific analysis of cytosine methylation and CTCF binding, revealed that CTCF does not regulate mono- or biallelic IGF2BP1 expression. Surprisingly, we found that RNA polymerase $I I$ is detected on both the maternal and paternal alleles in B lymphoblasts that express IGF2BP1 primarily from one allele. Thus, allele-specific control of RNA polymerase II elongation regulates the allelic bias of IGF2BP1 gene expression.

Conclusions: Colocalization of CTCF and H3K9me3 does not represent a reliable chromatin signature indicative of monoallelic expression. Moreover, association of individual alleles with both active (H3K4me3) and silent (H3K27me3) chromatin modifications (allelic bivalent chromatin) or with RNA polymerase II also fails to identify monoallelically expressed gene loci. The selection of individual alleles for expression occurs in part during transcription elongation.

\section{Background}

Allele-specific gene expression is an integral component of cellular programming and development and contributes to the diversity of cellular phenotypes [1,2]. Allelic differences in gene expression are mediated by either parent-of-origin-specific selection (imprinting) or stochastic selection of alleles for activation and/or silencing. The importance of genomic imprinting has recently been highlighted by RNA sequencing studies that demonstrated widespread allelic differences in gene

\footnotetext{
* Correspondence: akrumm@u.washington.edu

'Institute for Stem Cell and Regenerative Medicine, University of Washington School of Medicine, 815 Mercer St., Seattle, WA 98109, USA

Full list of author information is available at the end of the article
}

expression in mouse brain affecting more than 1,300 genes [3]. The extent of sex- and stage-specific expression of individual alleles emphasizes the essential role of allelic transcriptional regulation in development. In addition to the extensive occurrence of imprinted parent-of-origin-specific expression, gene expression patterns of clonal cell populations are also modified by random or stochastic silencing of either the maternal or paternal allele. Well-known loci displaying allele-specific expression include odorant receptor genes, immunoglobulins and various receptor proteins [4-6]. Additionally, previous large-scale studies have provided new data demonstrating that parent-of-origin-specific expression is employed much more frequently than previously

\section{Biomed Central}


thought [7]. These new findings illustrate the scale and complexity of genomic allele-specific expression. However, the precise molecular mechanism underlying the allelic bias in gene expression is not very well understood.

The best-characterized locus with strict monoallelic imprinted gene expression is the region containing the insulin-like growth factor 2 (IGF2) and $H 19$ genes [8]. The regulation of this locus relies on the imprinting control region (ICR), which acquires DNA methylation on the paternal allele during normal development of the male germline. Methylation of cytosines at the ICR inhibits binding of the zinc finger protein CTCF to the paternal allele, preventing its role as an insulator and allowing long-range interactions of the IGF2 promoter with enhancer elements downstream of the H19 gene [9-11]. In contrast, the unmethylated ICR on the maternal allele recruits CTCF, effectively preventing promoter-enhancer interactions and maintaining repression of the maternal IGF2 gene.

The well-documented requirement of CTCF for imprinted expression at the IGF2/H19 gene locus is thought to result from its role in establishing and/or maintaining long-distance interactions between regulatory elements [12]. Allele-specific binding of CTCF to the ICR has long been known to be essential for the formation of chromatin loops. While the precise mechanism of CTCF's role in long-distance chromatin interactions remains unknown, several studies have provided a rationale for the differential expression of the maternal and paternal IGF2 gene by revealing an interaction of CTCF with cohesin, a protein complex known for its requirement during sister chromatid cohesion in mitosis [13-16]. Chromosome conformation capture experiments in combination with RNA interference assays recently confirmed the CTCF and cohesin-dependent formation of higher-order chromatin structures at the IGF2/H19 and other gene loci [17-19].

In addition to DNA methylation, histone modifications also contribute to the maintenance of allele-specific expression. DNA methylation of ICRs is accompanied by repressive histone markers, including histone $\mathrm{H} 3$ trimethylated at lysine 9 (H3K9me3). In contrast, the unmethylated allele is characterized by permissive histone markers, including histone $\mathrm{H} 3$ trimethylated at lysine 4 [20]. Colocalization of epigenetic markers including DNA methylation and histone H3 dimethylated at lysine 9 has been exploited to identify epigenetically distinct parental alleles. Chromosomal regions displaying overlaps of euchromatin and heterochromatin-specific markers have been enriched for known imprinted genes [21].

Despite the importance of monoallelic expression in cellular development and differentiation, little is known about the establishment and maintenance of random monoallelic expression. The link between allele-specific binding of CTCF and monoallelic expression of the IGF2 gene prompted us to test whether the presence of CTCF and H3K9me3 specifies a chromatin arrangement which demarcates random monoallelically expressed alleles. Using array-based chromatin immunoprecipitation (ChIP-chip), we identified 293 loci displaying these chromatin markers. We selected the IGF2BP1 gene locus to further examine whether the presence of CTCF and H3K9me3 comprises a necessary chromatin arrangement for a specific expression profile analogous to the monoallelic behavior observed at the IGF2/H19 locus. Surprisingly, colocalization of CTCF and $\mathrm{H} 3 \mathrm{~K} 9 \mathrm{me} 3$ does not provide a reliable measure of monoallelic binding of CTCF at the IGF2BP1 gene. Our studies included allele-specific sequencing of immunoprecipitated chromatin to demonstrate that chromatin at each IGF2BP1 allele is bivalent. Importantly, both alleles recruit RNA polymerase II, suggesting that silencing of one IGF2BP1 allele occurs after transcription initiation. By establishing which epigenetic configurations are involved in governing monoallelic gene expression, we will broaden the understanding of epigenetic mechanisms as they relate to cancer progression and cellular differentiation.

\section{Results}

\section{Colocalization of CTCF and H3K9me3 in the human} genome

Allele-specific binding of CTCF to the ICR regulates parent-of-origin-specific expression of the IGF2 gene and correlates with differential cytosine methylation and the presence of H3K9me3 [9-11]. We carried out a large-scale survey to identify genomic sites with chromatin markers similar to those at the ICR of the IGF2/H19 locus. Using ChIP-chip, we identified CTCF binding sites by tiling through the nonrepetitive portion of the genome in 100-bp intervals. Genomic sites bound by CTCF were assembled on a condensed array set that tiled through 9,823 sites using overlapping probes, and replicate ChIP experiments were performed. By using conservative criteria (positive signal in three replicates; $P$ $<0.05$ ) in this analysis, we identified 8,462 loci that interact with CTCF. To identify the subset of sites that associate with both CTCF and $\mathrm{H} 3 \mathrm{~K} 9 \mathrm{me} 3$, we tested the association of these 8,462 loci with H3K9me3 using the condensed DNA array set. These analyses revealed 293 loci that are both bound by CTCF and marked by H3K9me3 (Table S1 in Additional file 1) (distances of CTCF and H3K9me3 peaks < 500 bp). Of the 293 loci, 115 directly mapped to coding regions. Of the remaining loci (174 of 293), the majority (147 loci) were located in intergenic regions at a distance $>10 \mathrm{~kb}$ to 
the nearest 5' end of known genes. Only 27 loci mapped to promoter regions. Overall, $40 \%$ of the CTCF/ H3K9me3 loci mapped to intergenic regions, 51\% mapped to intragenic domains and $9 \%$ mapped to promoter regions, a distribution similar to that of the 8,462 CTCF loci (44\%, 51\% and 10\% respectively). Notably, the CTCF-regulated IGF2/H19 locus is included in the subset of 293 loci (Figure S1 in Additional file 2), suggesting that our experimental approach may be useful for the identification of similarly expressed genes.

\section{IGF2BP1 alleles are stochastically expressed in human B cells}

Genes classified as "monoallelically expressed" encompass both imprinted genes, such as the IGF2 gene, where monoallelic expression is regulated in a parentof-origin-specific manner, and stochastic loci, where individual alleles are randomly selected for expression independent of parental origin. In recent studies in which allele-specific transcription was assessed in several human cell lines, more than 300 (7.5\%) of 4,000 human genes examined were subject to random monoallelic expression, with a majority of the latter being capable of biallelic expression [7].

To examine whether CTCF binding at sites marked by $\mathrm{H} 3 \mathrm{~K} 9 \mathrm{me} 3$ is indicative of monoallelic expression, we first compared the genomic positions of our 293 loci with the list of genes expressed in a random allele-specific manner. Only a small number of genes (8 of 293 loci) were common to both the monoallelically expressed cohort described by Gimelbrant et al. [7] and our CTCF/H3K9me3 set of ChIP-chip binding loci.

To further examine the correlation between CTCF/ H3K9me3 and monoallelic expression, we selected 12 genes located near one of the $293 \mathrm{CTCF} / \mathrm{H} 3 \mathrm{~K} 9 \mathrm{me} 3$ sites (DIAPH1, FUS1, PKP1, ARFGAP2, PCDHGA, MTHFR, LAIR1, GPR3, ARMET, NPR1, NHLRC1 and IGF2BP1) to search lymphoblastoid cell lines (LCLs) derived from a pedigree from the Center d'Etude du Polymorphisme Humaine $(\mathrm{CEPH})$ for SNPs in exonic and 3'-UTR regions. The monoclonality of LCLs was confirmed by analysis of their immunoglobulin heavy chain $(\mathrm{IgH})$ gene rearrangement (Figure S2 in Additional file 2) [22]. Sequencing of genomic DNA (gDNA) and cDNA of LCLs identified the insulin-like growth factor binding protein gene IGF $2 B P 1$ as the only candidate gene expressed from only one allele (Table S2 in Additional file 1). IGF2BP1 is an RNA-binding protein that regulates transcript stability and translation of the imprinted IGF2 gene [23]. In addition, IGF2BP1 binds to $\mathrm{H} 19$, MYC and $\beta$-TrCP1 mRNA to regulate message half-life, localization and translation of RNA, suggesting that the regulation of IGF2BP1 expression may affect disease and development [24,25]. We focused on IGF2BP1 to examine the contribution of CTCF and H3K9me3 markers colocalized at intron 5 to allele-specific expression (Figure 1).

Sequencing of gDNA identified 10 individuals that were heterozygous at SNP rs11655950 in the 3'-UTR of IGF2BP1 (Figure 2A). All heterozygous SNPs were subsequently typed in cDNA. A comparison of the transcriptome-derived genotypes to genomic genotypes indicated that six individuals expressed IGF2BP1 primarily from only one allele. In contrast, four individuals were found to express both IGF2BP1 alleles (Figure 2A). SNP determination for genomic and cDNA for $\mathrm{CEPH}$ family 1331 was confirmed by allelic discrimination assays based on fluorogenic probes (TaqMan allelic discrimination assay; Applied Biosystems, Foster City, CA, USA), which yielded identical results (Figure S3 in Additional file 2). The TaqMan allelic discrimination assay, a real-time PCR based approach, yields a scatterplot of genotypes capable of quantitatively detecting a range of 1:1 and 1:5 ratios of individual alleles in DNA mixtures at SNP rs11655950 (Figure S4 in Additional file 2). Individuals GM7033 and GM6989 were found to express the paternally inherited IGF2BP1 allele, while GM7030 and GM7005 were found to express the maternally inherited allele (Figure 2). Individuals GM7007 and GM7016 also exhibited monoallelic expression of $I G F 2 B P 1$, but we were unable to identify the mode of expression because of the limited pedigree. These data indicate that monoallelic expression at the IGF2BP1 gene locus is not determined by parent-of-origin markings; instead, it is defined by stochastic choice.

\section{CTCF binds to its target motif at the IGF2BP1 locus independently of DNA methylation}

Binding of CTCF to its target motifs at both the human and mouse ICR of the IGF2/H19 locus is sensitive to DNA methylation $[10,26]$. To test whether monoallelic expression of IGF2BP1 in some individuals is also regulated by monoallelic DNA methylation of CTCF binding motifs, we examined a role for $\mathrm{CpG}$ methylation and allele-specific binding of CTCF at this locus.

To precisely determine the DNA sequence required for CTCF binding at the IGF2BP1 locus, we searched for potential motifs using SOMBRERO [27], a de novo motif-finding algorithm that uses multiple self-organizing maps $(\mathrm{SOM})$ to cluster sequences of a specific length (reads) from a set of input sequences (such as enriched genomic loci identified by ChIP-chip experiments). Motif alignment using STAMP [28] and comparison to the JASPAR transcription factor database [29] identified a distinct cohort of 68 motif models, all of which were identical to the canonical CTCF motif previously reported (Figure S5 in Additional file 2) [30]. The clustered reads associated with all 68 motif models 


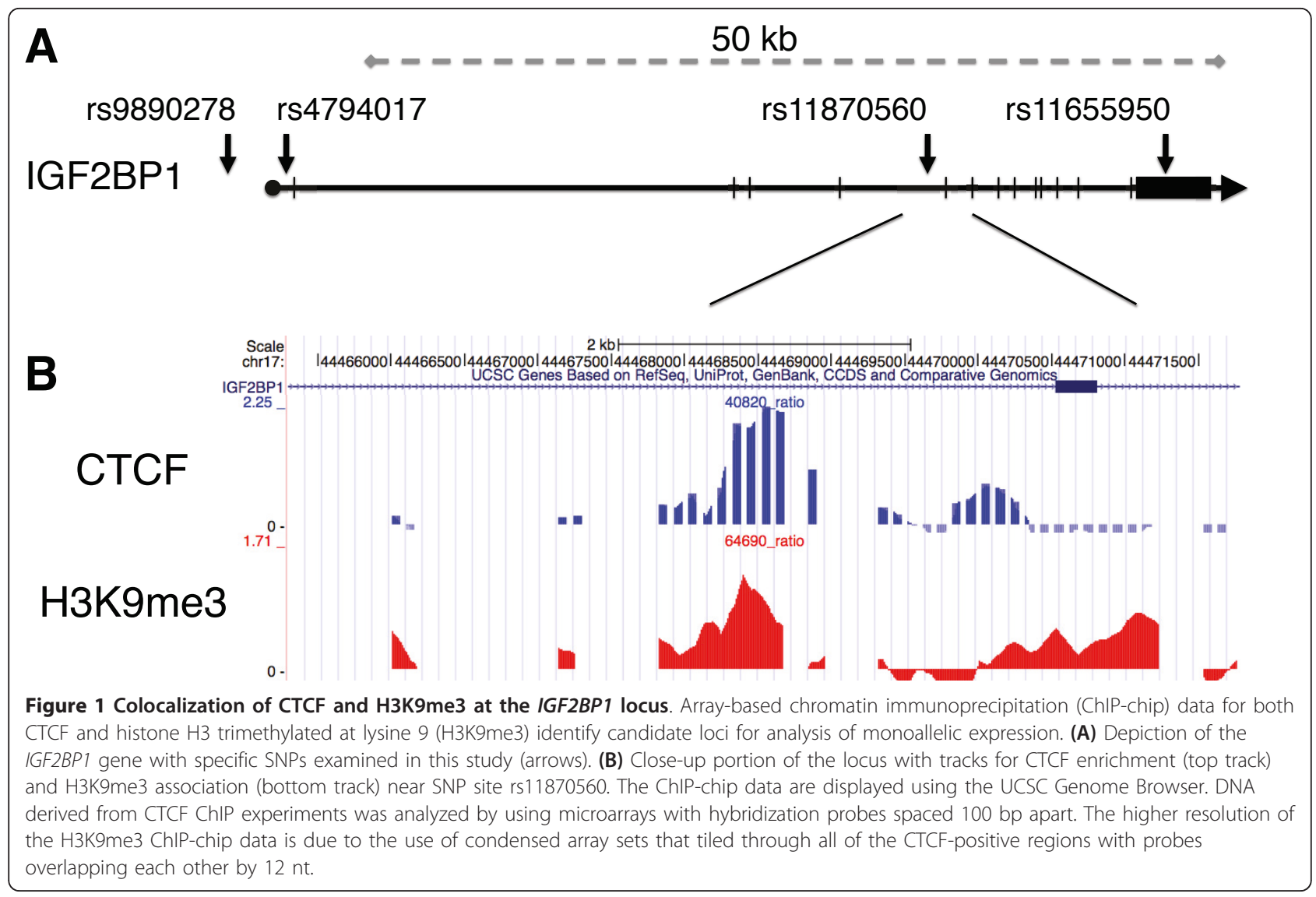

were mapped back to sequences enriched in our ChIPchip analysis and were displayed using the UCSC Genome Browser (Figure S6 in Additional file 2). Using this approach, we identified 28,713 peaks, each composed of multiple overlapping reads, within the original 8,462 ChIP-chip loci. Using a strategy similar to that used to study ChIP-seq clustering [31], our frequency analysis of these peak heights yielded a bimodal distribution with an evident power law at low peak heights deviating to a clear excess in the numbers of peaks with heights $>10$ (Figure S7 in Additional file 2). We consequently partitioned the peak populations into low-confidence and high-confidence groups using the peak height threshold of 10 (Figure S8 in Additional file 2).

Using this approach, we identified three potential motifs (X, Y and Z) (Figure 3) within the 350-bp region of the IGF2BP1 gene locus enriched in our ChIP-chip experiments. Two of the putative binding sites, $\mathrm{Y}$ and $\mathrm{Z}$, accumulated a significant number of matches to motif models. However, only one of the three putative CTCF binding sites belongs to the group of high-confidence binding sites (site Y) (Figure 3). In support of our in silico analysis of CTCF binding, previously published high-resolution ChIP-seq data on CTCF binding revealed enrichment of sequences surrounding motifs $\mathrm{Y}$ and $\mathrm{Z}$ (Figure 3A), suggesting that either one or both motifs is required for CTCF recruitment.

To further define the contribution of motifs $\mathrm{Y}$ and $\mathrm{Z}$ to CTCF binding, we measured their ability to recruit CTCF in vitro using immobilized template assays (Figures $3 \mathrm{~B}$ and $3 \mathrm{C}$ ). Wild-type and mutant DNA templates containing either one or both motifs were linked to magnetic beads, incubated with nuclear extract, washed and tested for association with CTCF by performing Western blot analysis. A 105-bp template containing the wild-type IGF2BP1 intronic sequence efficiently recruited CTCF ( $Y^{\mathrm{wt}} 105$-bp template) (Figure 3B). In contrast, CTCF binding was severely reduced when the putative CTCF motif Y was mutated by four base substitutions (Figure $3 \mathrm{C}$ and Figure S9 in Additional file 2). To test the contribution of the adjacent motif $\mathrm{Z}$ to CTCF binding at the IGF2BP1 locus, we generated several 125-bp DNA templates that encompassed both CTCF target motifs (Figure $3 \mathrm{~B}$ ). Targeted mutations at specific positions of motif $\mathrm{Y}$ and/or motif $\mathrm{Z}$ were introduced to test the contribution of each motif to recruitment of CTCF. Detailed sequences are shown in Figure S9 in Additional file 2. As shown in Figure 3C, the 125bp template recruited CTCF more efficiently than the 105-bp template. However, motif $\mathrm{Z}$ does not contribute 


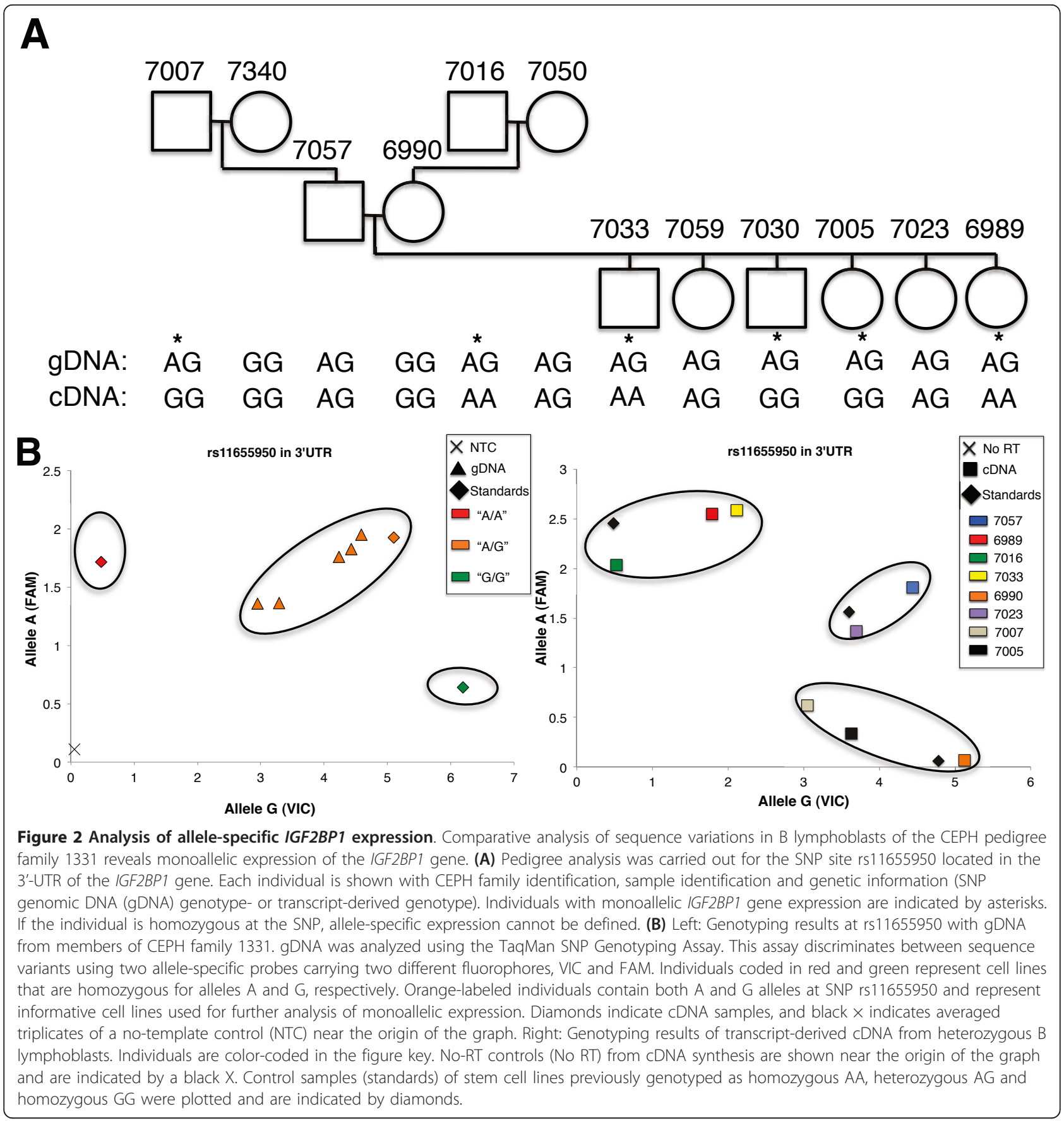

to CTCF recruitment, since targeted mutations in motif $\mathrm{Z}$ do not influence the level of CTCF binding. Consistent with this notion, CTCF binding is undetectable in the absence of a wild-type motif $Y$ (Figure $3 \mathrm{C}$ ).

CTCF binding site $\mathrm{Y}$ at the IGF2BP1 gene contains a single $\mathrm{CpG}$ residue adjacent to the 14-bp core sequence of CTCF (Figure 4A). To establish whether binding of CTCF to $\mathrm{Y}^{\mathrm{wt}}$ is inhibited by cytosine methylation, we tested $\mathrm{Y}^{\mathrm{wt}}$ 105-bp immobilized templates after in vitro methylation of cytosine residues by $\mathrm{CpG}$ methyltransferase M.Sssl. For comparison, we examined CTCF motifs containing a higher CpG content, including site A of the MYC gene [32] as well as the B1 sequence of the ICR of the human IGF2/H19 locus [10]. Cytosine methylation at the human $\mathrm{B} 1$ sequence is known to inhibit binding of CTCF. Consistent with this, recruitment of CTCF in vitro to immobilized templates containing the B1 sequence or the MYC site A is highly sensitive to DNA methylation (Figure 4B, top). In contrast, $\mathrm{CpG}$ methylation of the $\mathrm{Y}^{\mathrm{wt}}$ motif has no effect on CTCF recruitment. Replacement of the $\mathrm{Y}^{\mathrm{wt}}$ core 


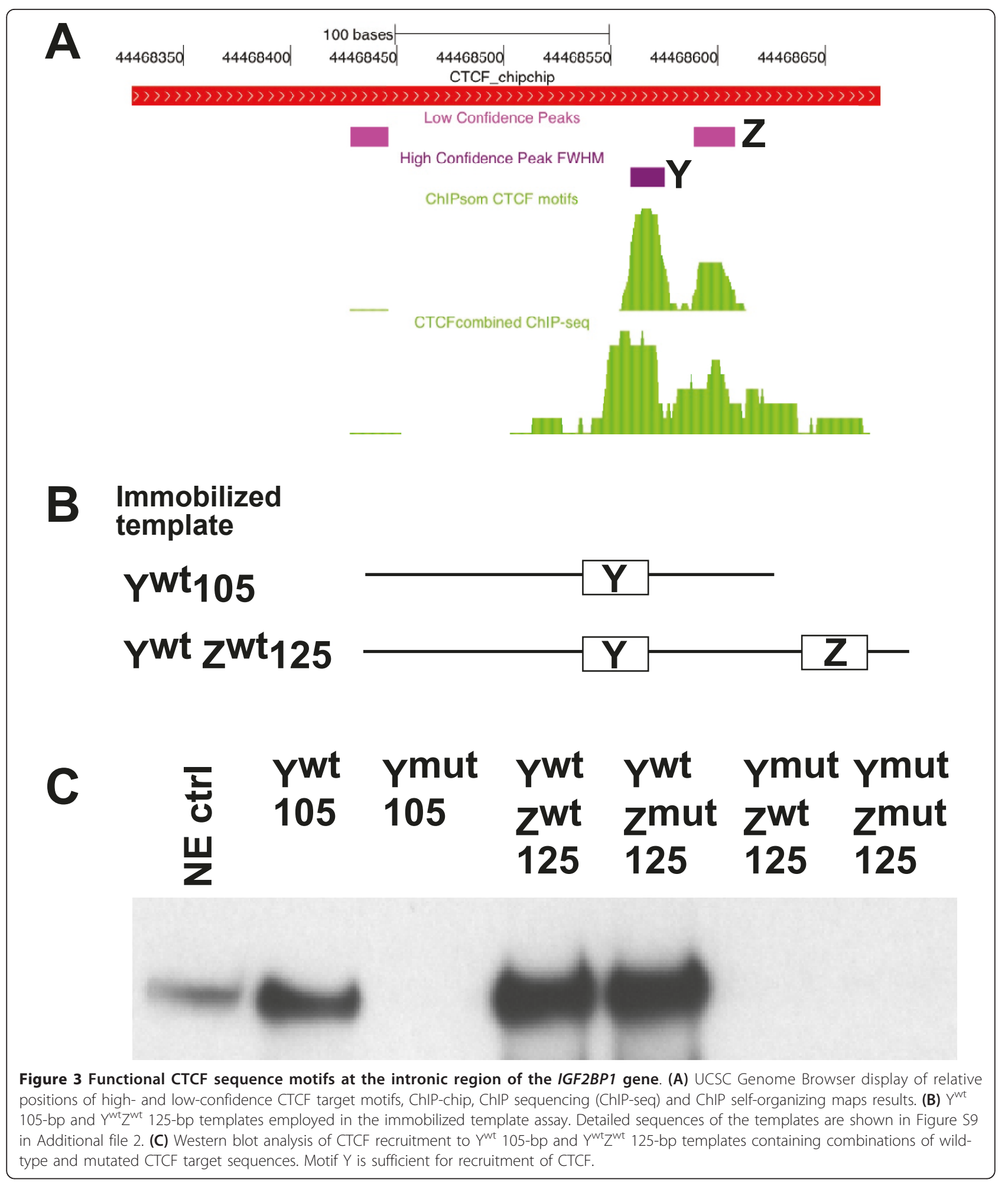

motif by the CTCF-binding sites of the chicken FII insulator element yields similar results. However, CTCF binding becomes sensitive to $\mathrm{CpG}$ methylation upon modification of the core motif to the mouse R3 sequence, a homologue of the human B1 sequence. In combination, despite the presence of a methylable $\mathrm{CpG}$ residue, binding of $\mathrm{CTCF}$ to the $\mathrm{Y}^{\mathrm{wt}}$ sequence of the IGF2BP1 gene in vitro is not sensitive to CpG methylation. 
A
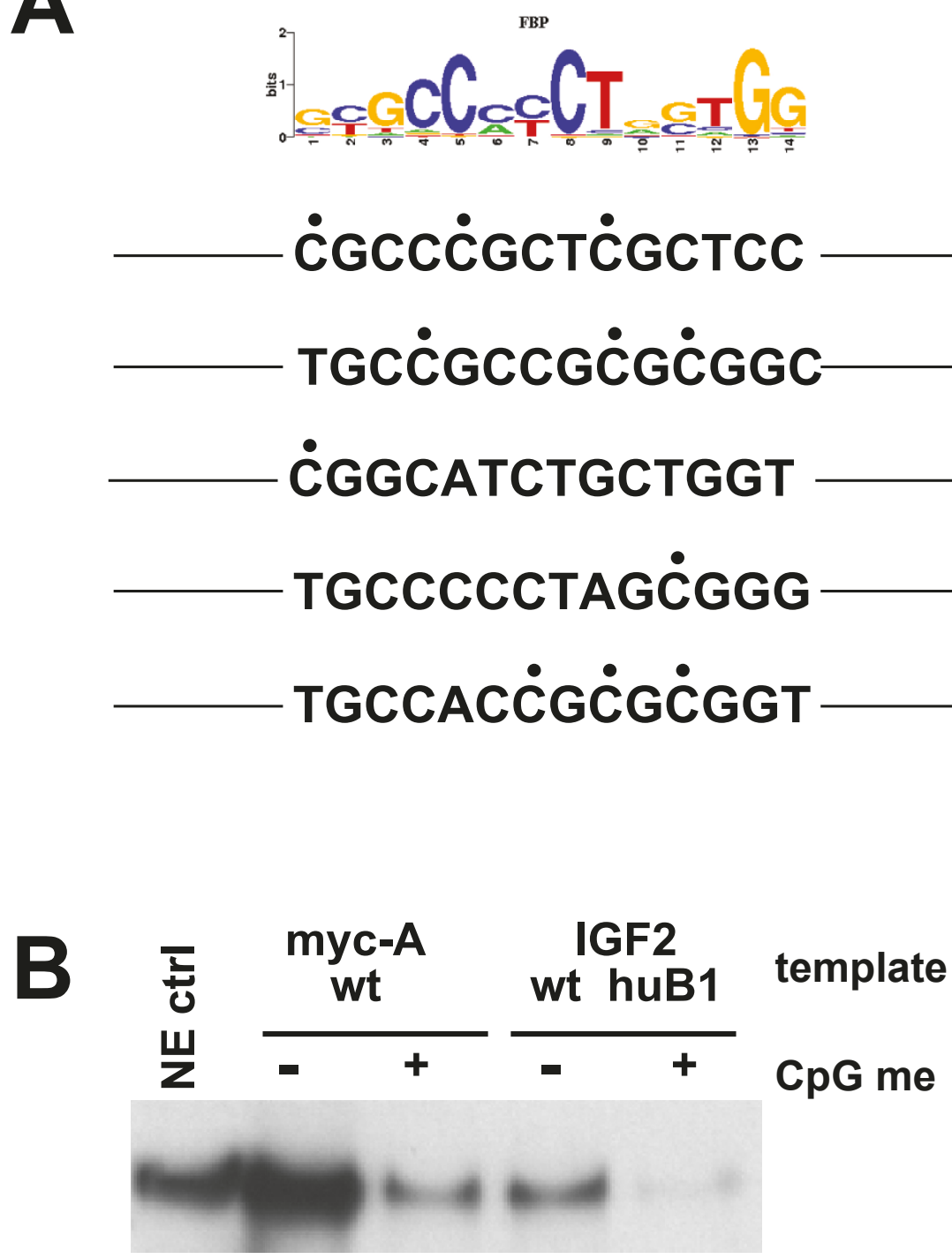

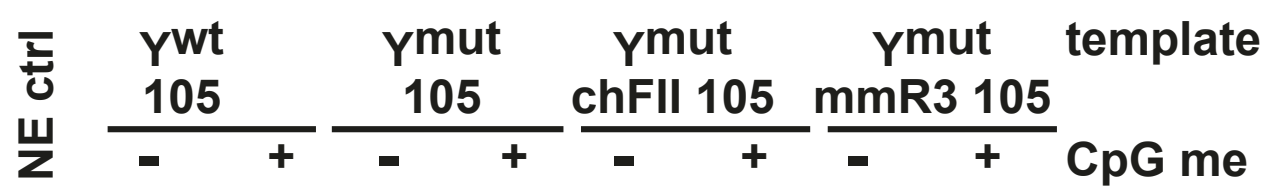

Figure 4 Cytosine methylation of the CTCF core motif $Y$ does not influence binding of CTCF. (A) CTCF motifs used in the context of the 105-bp immobilized template derived from the intronic region of the IGF2BP1 gene are shown. The position frequency matrix of the CTCF target motif is shown at the top. Only the sense strand of the motifs is shown. CpG residues are indicated by filled black circles. Myc-A, IGF2 huB1 and $Y^{\text {wt }}$ are CTCF target sequences derived from MYC, IGF2 and IGF2BP1 gene loci. $Y^{\text {mut }}$ chFIl and $Y^{m u t}$ mmR3 contain the CTCF target sequence of the chicken HS4 insulator [57] and the CTCF target region of the mouse imprinting control region R3 [10]. (B) Top: control experiments revealed the sensitivity of CTCF binding to DNA methylation (CpG me) at the myc-A and IGF2 huB1 templates. Bottom: methylation of the 105-bp Ywt template did not affect the recruitment of CTCF. While methylated chicken FII CTCF target sites efficiently recruited CTCF, CpG methylation of the mouse R3 sequence decreased the binding of CTCF. 
To confirm that our in vitro characterization of CTCF binding accurately reflected the in vivo association of CTCF with the IGF2BP1 locus, we evaluated the methylation status of the CTCF motif and adjacent CpG residues in the IGF2BP1 intronic region in both biallelically (GM7057) and monoallelically (GM6989) expressing cells by using bisulfite sequencing (Figure 5). The methylation levels were calculated using BiQ Analyzer software [33]. Our data reveal that the CpG residue at the 5' end of the CTCF binding motif $\mathrm{Y}$ is invariably methylated. In addition, other methylable residues in this region exhibited some degree of DNA methylation. To further confirm binding of CTCF to methylated IGF2BP1 intronic sequences, we bisulfite-sequenced DNA derived from immunoprecipitates of ChIP experiments with CTCF antibodies. As a control, we bisulfitesequenced the IGF2BP1 region derived from antiH3K9me3 ChIP experiments. The results confirmed our in vitro finding that demonstrated an association of CTCF with a methylated motif (Figures 5B and 5C).

CTCF and H3K9me3 colocalize at both the maternal and paternal IGF2BP1 alleles

Consistent methylation of the CTCF-binding motif in $I G F 2 B P 1$ indicated that DNA methylation is not allelespecific. To directly determine whether CTCF is bound monoallelically, we determined the allele-specific association of both CTCF and H3K9me3 by sequencing DNA recovered from ChIP experiments. We first identified informative cell lines by genotyping individuals from CEPH pedigree 1331 at SNP sites located close to the CTCF binding site. Cell lines derived from both monoallelically (GM7016 and GM6989) and biallelically (GM7057) expressing individuals were heterozygous at SNP site rs11870560 at the CTCF site (Figure 6A). We first applied the allelic discrimination assay to serial

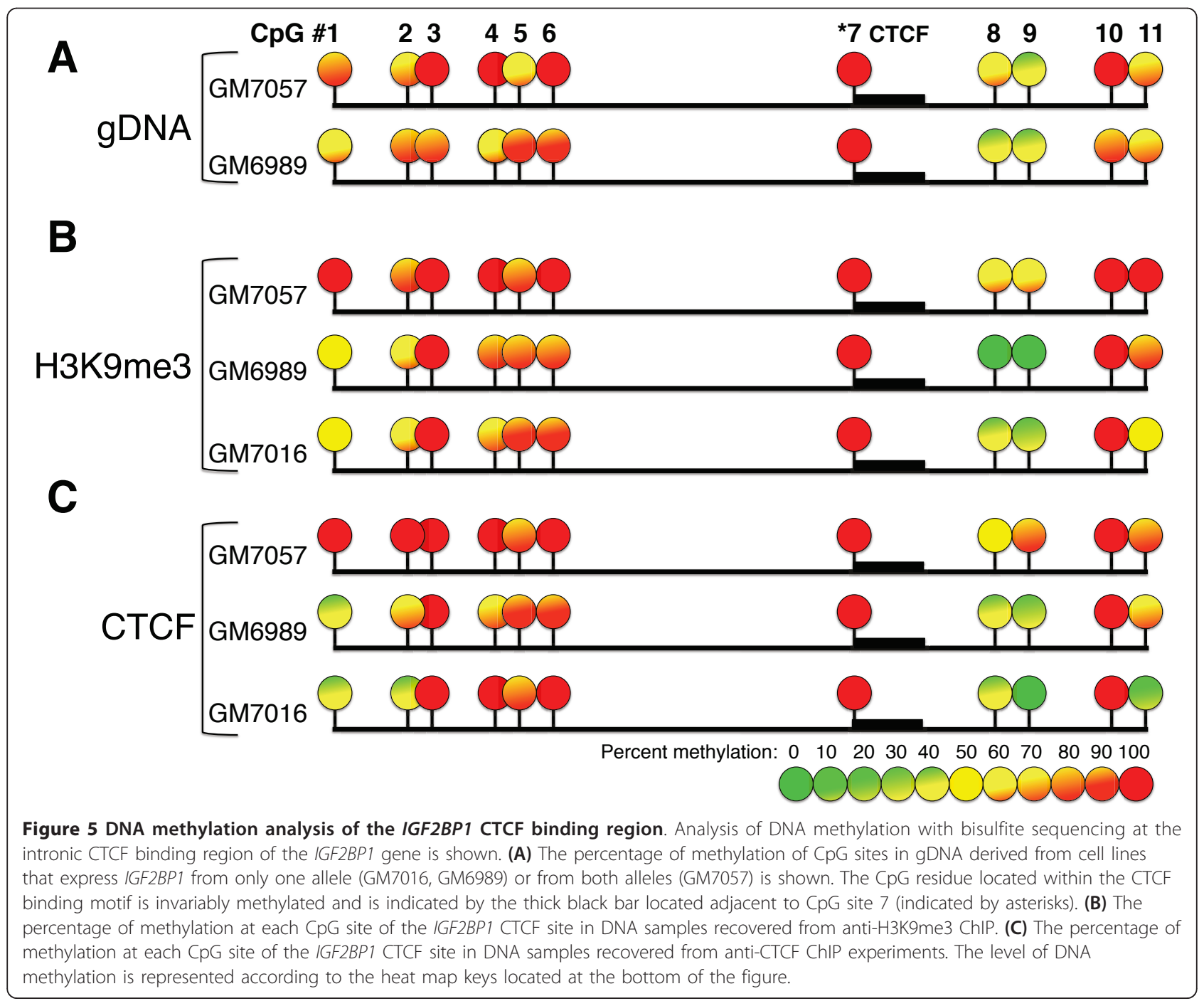




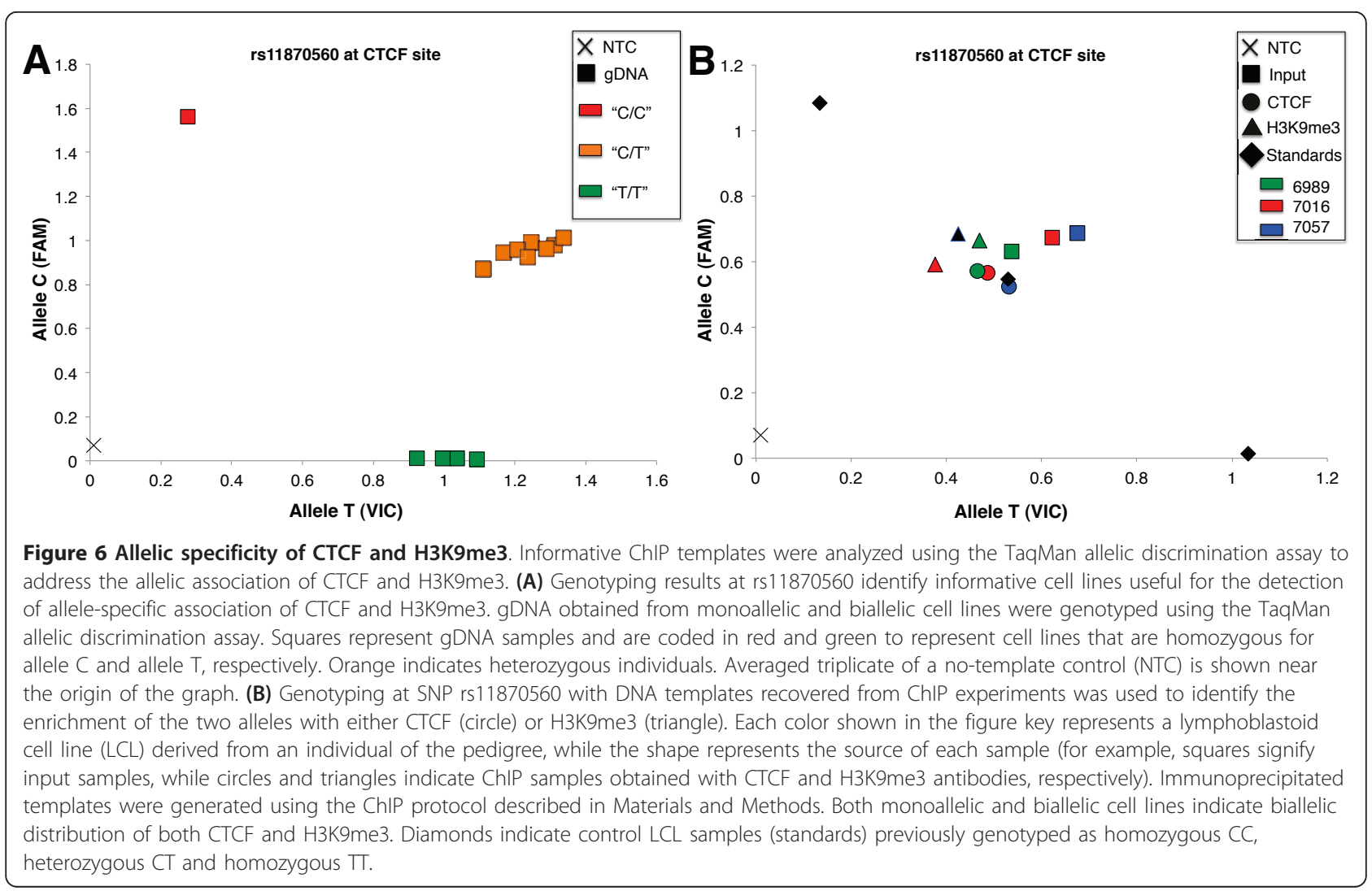

dilutions of known homozygotes of the two possible alleles to test its ability to quantitatively assess the contribution of each allele in a DNA mixture. This assay provides quantitative results with high sensitivity and reproducibility within a ten-fold range of DNA concentrations, thus making it a useful tool for allelic discrimination of immunoprecipitated DNA (Figure S4 in Additional file 2). We used two monoallelically (GM7016 and GM6989) and one biallelically (GM7057) expressing cell lines to genotype DNA recovered from ChIP assays using either anti-CTCF or anti-H3K9me3 antibodies. Each analysis was performed in triplicate. Equal proportions of the two sequence variants were detected in DNA derived from ChIP assays with either H3K9me3 or CTCF antibodies, indicating that CTCF associates with both the maternal and paternal alleles (Figure 6B). Thus, monoallelic expression of the $I G F 2 B P 1$ gene is not mediated through monoallelic binding of CTCF.

The IGF2BP1 promoter associates with both active and silent histone modifications in $B$ cells

To define alternative mechanisms responsible for random monoallelic expression of IGF2BP1, we sought to identify markers that distinguish the active and inactive alleles. K27-trimethylated and K4-trimethylated histone
$\mathrm{H} 3$, respectively, mark transcriptionally silent and active chromatin. We determined the relative enrichment of these two histone markers at the IGF2BP1 promoter for each allele in both monoallelically and biallelically expressing cell lines using ChIP with anti-H3K4me3 and anti-H3K27me3 antibodies. Both H3K4me3 and $\mathrm{H} 3 \mathrm{~K} 27 \mathrm{me} 3$ were detected at the IGF2BP1 gene promoter (Figure 7A). To determine whether any of the histone modifications selectively associates with either allele, we again searched for informative sequence SNPs at the IGF2BP1 promoter region in the CEPH pedigree. Cell lines derived from individuals GM6989 (monoallelically expressing cell line) and 7057 (biallelically expressing cell line) were heterozygous at SNP rs9890278 located upstream of the transcription initiation site, whereas GM7007 (monoallelically expressing cell line) was heterozygous for SNP rs4794017 located $1 \mathrm{~kb}$ downstream of the transcription initiation site. To address whether active and silent alleles in these cell lines are distinguished by specific histone markers, we sequenced SNPs rs9890278 and rs4794017 in gDNA recovered from ChIP experiments using anti-H3K4me3 and anti-H3K27me3 antibodies. The results revealed that both H3K4me3 and H3K27me3 are detected on both alleles in a bivalent fashion (Figure 7). In combination, our results indicate that both active and silent 


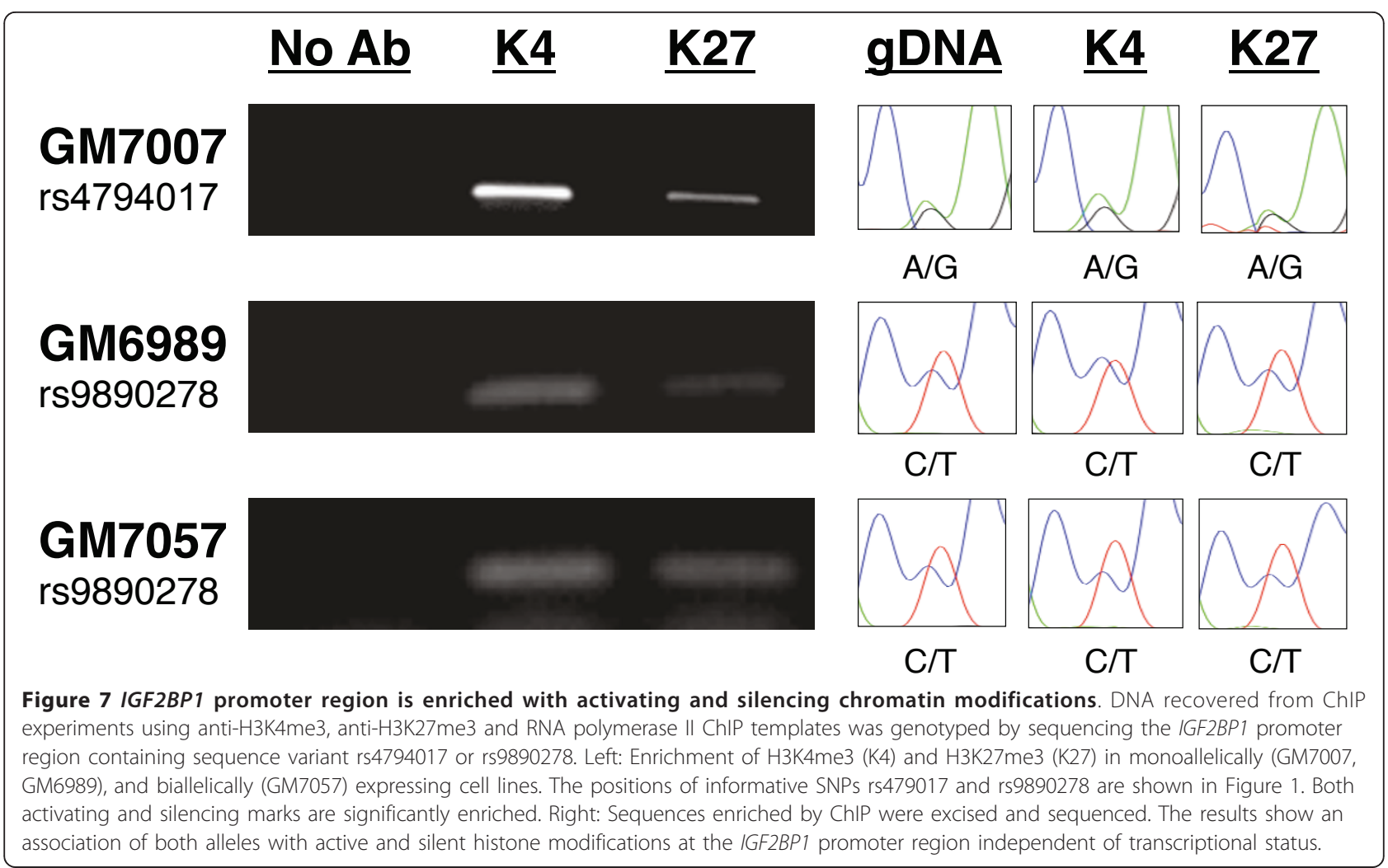

histone markers (H3K4me3 and H3K27me3) coexist in the promoter region of both IGF2BP1 alleles in monoallelically as well as biallelically expressing cell lines. These data indicate that allele-specific expression of $I G F 2 B P 1$ cannot be explained by differential association of active and silent histone markers.

\section{Silencing of the inactive IGF2BP1 allele by inhibition of RNA polymerase II elongation}

Monoallelic expression of IGF2BP1 cannot be attributed solely to selective activation or silencing of one allele through histone modifications, since H3K4me3 as well as $\mathrm{H} 3 \mathrm{~K} 27 \mathrm{me} 3$ are detected at both alleles. H3K4me3 is typically associated with transcriptionally active alleles, raising the question whether allele-specific transcription elongation or RNA processing accounts for monoallelic expression of the IGF $2 B P 1$ gene. To address this hypothesis, we again searched mono- and biallelically expressing cell lines for sequence SNPs near the site of transcription initiation at the IGF2BP1 promoter. Within CEPH pedigree 1331, only line GM7007 contained a heterozygous genotype at SNP site rs4794017 located within intron 1, $1 \mathrm{~kb}$ downstream of the transcription initiation site. We performed RNA polymerase II ChIP on chromatin prepared from this monoallelically expressing line. Quantitative real-time PCR analyses revealed enrichment of $I G F 2 B P 1$ promoter sequences similar to the enrichment observed at the MYC promoter. Immunoprecipitated DNA was PCR-amplified and sequenced (Figure 8A). Identification of both sequence variants at rs4794017 in DNA recovered from ChIP experiments indicates that RNA polymerase II is associated with both IGF2BP1 alleles, which is consistent with the presence of $\mathrm{H} 3 \mathrm{~K} 4 \mathrm{me} 3$ at the promoter of both alleles.

These data suggest that allele specificity of transcription is achieved after recruitment of RNA polymerase to both alleles, such as through transcriptional pausing and/or selective RNA processing. A major rate-limiting step in transcription elongation is pausing of RNA polymerase II in the promoter proximal region immediately downstream of the transcription initiation site [34-37]. We sequenced the 5 ' portion of the IGF2BP1 gene of all monoallelically expressing cell lines to identify sequence variants that would be useful for allelic identification of promoter proximal regions occupied by RNA polymerase II or for the determination of the allelic origin of unspliced, precursor pre-mRNA transcripts. Since no additional informative sequence variants were identified, we focused on the detection and sequencing of premRNA transcripts about $1 \mathrm{~kb}$ downstream of the transcription initiation site in GM7007. Using the informative SNPs located within intron 1 of this gene, we targeted nascent unspliced RNA with primers designed 


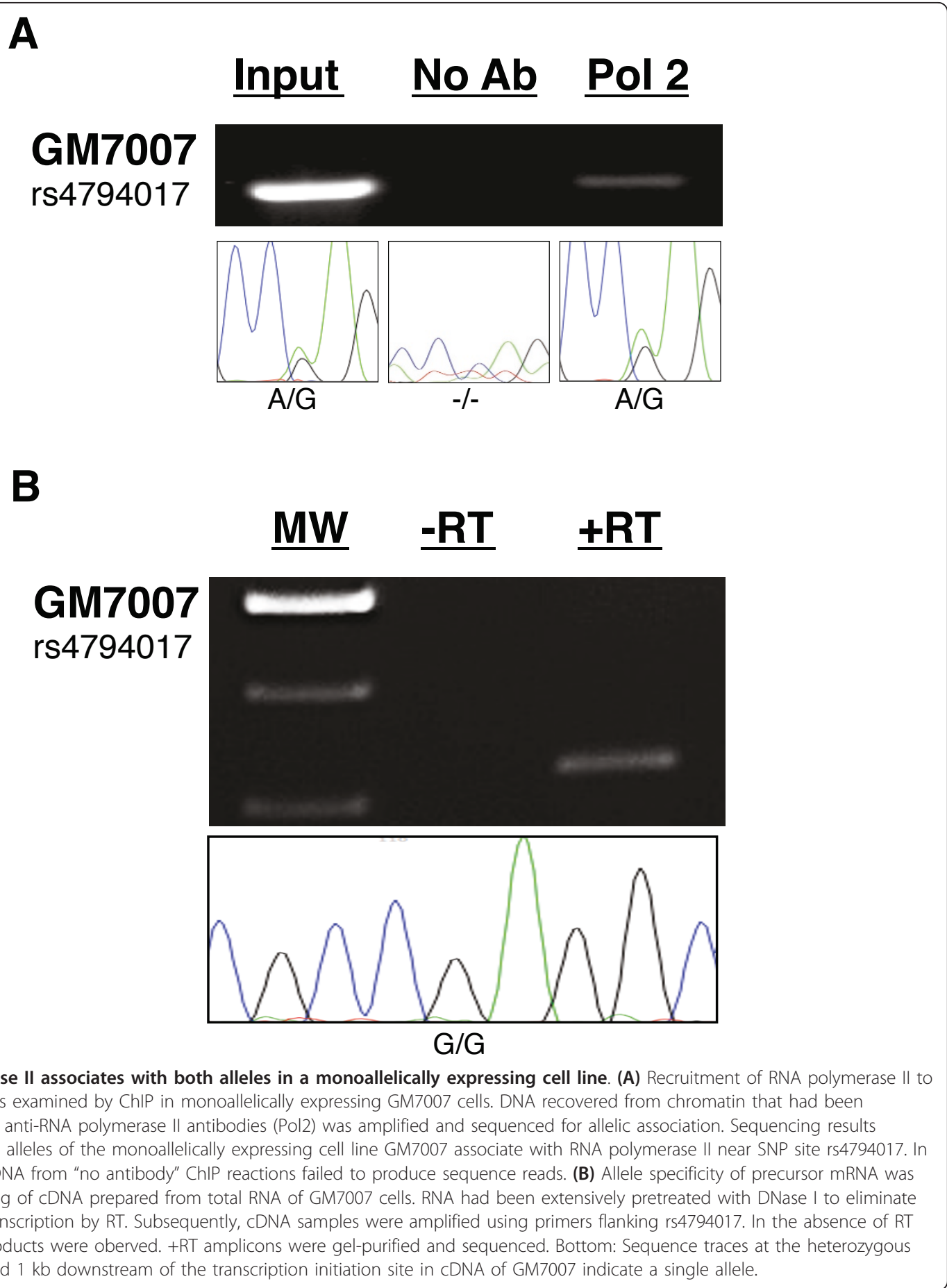

to amplify a region containing SNP site rs4794017. To avoid detection of gDNA in RNA samples, DNA was efficiently removed by treatment with an engineered, highly active form of DNase I (TURBO DNase I; Applied Biosystems/Ambion, Austin, TX, USA). This protocol allowed detection of pre-mRNA free of gDNA contamination (Figure 8B). Sequencing of amplified
IGF2BP1 pre-cDNA revealed only one of the two sequence variants at SNP rs4794017, indicating that premRNA transcripts are transcribed from only one allele despite the presence of RNA polymerase II on both alleles. Thus, our data indicate that monoallelic expression of the IGF2BP1 gene is regulated through allelespecific transcriptional elongation prior to SNP site 
rs4794017, located approximately 600 bp downstream of the first intron splice site.

\section{Discussion}

Allele-specific expression in which one parental allele is stochastically or parent-of-origin-specifically silenced is widespread in mammalian organisms. Large-scale, allelespecific gene expression analyses have revealed that 5\% to $10 \%$ of autosomal genes show random monoallelic transcription [7]. The stability of allele-specific expression through many cell passages suggests that epigenetic modifications maintain this specific type of gene regulation throughout generations of cells. Analogously to the regulation at the imprinted IGF2/H19 locus, we tested the hypothesis whether monoallelic binding of CTCF, a characteristic marker for the IGF2/H19 ICR, also underlies random monoallelic expression. Using ChIP-chip analyses, we identified chromosomal loci that are enriched in both CTCF and H3K9me3 and cross-correlated their positions with previously published lists of monoallelically expressed genes. Our data indicate that genomic loci enriched for both CTCF and H3K9me3 do not significantly correlate with monoallelically expressed genes. While this lack of correlation could be formally attributed to variations in monoallelic expression between different cell lines and types, it should be noted that the genome-wide pattern of CTCF binding is very consistent between different cell lineages [30,38,39]. Thus, if CTCF and H3K9me3 contribute to allele-specific expression, it should be detectable through allele-specific association of CTCF and H3K9me3. Focusing on the IGF2BP1 gene, we tested whether monoallelic expression in a pedigree of LCLs correlates with monoallelic binding of CTCF. Although binding of CTCF to its targets is thought to be sensitive to DNA methylation, we surprisingly found the cytosine residue closely flanking the CTCF target motif at the IGF2BP1 gene to be consistently methylated without any effect on CTCF recruitment. Indeed, our in vitro analyses of the binding requirements using immobilized templates confirmed that methylation of cytosine residues within the IGF2BP1 sequence does not affect CTCF binding. These data are consistent with those in previous studies in which researchers found that cytosine methylation outside the CTCF core motif did not affect the binding affinity of bacterially expressed wild-type and mutant CTCF proteins [40]. This information is useful for the identification of the genomic subset of CTCF sites that might contribute to differential cell- and stage-specific expression due to their sensitivity to cytosine methylation, potentially mediating changes in large-scale chromatin organization during development and disease.

A number of studies have examined the correlation of allele-specific expression with allele-specific association of epigenetic markers [21,41-45]. The data produced by these studies have established common signatures of imprinted alleles, including H3K9me3 and H3K4me3, providing a powerful means by which to identify novel imprinted or monoallelically expressed loci [46-48]. In contrast to the strict allele-specific association of DNA methylation and chromatin markers at imprinted genes, histone modifications at the nonimprinted, monoallelically expressed IGF2BP1 gene do not predict the active allele. Both H3K4me3 and H3K27me3, markers characteristic of active and inactive loci, are associated with each allele, as both sequence variants of SNP rs4794017 are present in the DNA of heterozygous individuals recovered from ChIP experiments. Moreover, loading of RNA polymerase II also does not provide a reliable marker for identifying the transcribed allele. Our ChIP experiments identified both sequence variants at SNP rs4794017 within the promoter proximal region of antiRNA polymerase II immunoprecipitated DNA. Because only one LCL in our study was informative for determining an association of RNA polymerase II at the IGF2BP1 alleles, we could not define how frequently this type of regulation occurs within cell lineages and throughout the genome. However, other investigators have reported similar results at the PCNA gene. Maynard et al. [44] found that both PCNA alleles in IMR90 cells are bound by RNA polymerase II, although only one allele generates full-length mRNA. Together, these data suggest that transcription elongation not only is a general rate-limiting step in the transcription of the vast majority of genes $[34,35,37]$ but also regulates the expression of a subset of monoallelically expressed genes.

The expression of IGF2BP1 in differentiated cell types, including LCLs, is significantly lower than in embryonic stem cells. In an attempt to determine whether allelespecific expression also contributes to IGF2BP1 regulation early in development, we genotyped both gDNA and cDNA in 11 human embryonic stem cell (hESC) lines. However, while only three hESC lines were informative (heterozygous at SNP rs11655950), all three expressed IGF2BP1 in a biallelic manner. Although the number of available and informative hESC lines is not sufficient to clearly define a role for allele-specific elongation in early developmental stages, we believe that it is unlikely that this mechanism is restricted to cell types with low levels of IGF2BP1 expression. Control of transcriptional activity through promoter proximal pausing or premature termination of transcription is not restricted to specific gene classes characterized by low levels of transcriptional activity [35]. We speculate that distinct positioning of the homologous alleles within the nuclear space and association with distinct "transcription factories" may contribute to monoallelic transcription elongation. 
The IGF2BP1 gene is highly expressed during embryonic development and is required for the regulation of mRNA stability of several genes involved in growth regulation, including the IGF2, $\beta$-catenin and $M Y C$ genes [23-25]. Consistent with its role in early developmental stages, the IGF2BP1 gene is downregulated in differentiated cell types, and overexpression of IGF2BP1 is known to occur in multiple human cancers, including breast, lung and colon [49-52]. Thus, changes in the level of IGF2BP1 expression through silencing of only one allele could provide a safeguard against pathogenesis and disease.

\section{Conclusions}

Allele-specific gene expression is common in the human genome and is thought to contribute to phenotypic variation. The allele-specific association of CTCF, H3K9me3 and DNA methylation is a characteristic marker of imprinted gene expression at the IGF2/H19 locus, raising the question whether these epigenetic markers are useful for identifying both imprinted and random monoallelically expressed genes throughout the genome. In this study, we have demonstrated that colocalization of CTCF and H3K9me3 does not represent a reliable chromatin signature indicative of monoallelic expression. In addition, we conclude that allele-specific binding of CTCF requires methylation of very specific cytosine residues within the target motif, effectively limiting the number of CTCF binding sites potentially affected by allele-specific binding. In addition, the active and inactive alleles of random monoallelically expressed genes do not necessarily correlate with active or inactive histone markers. Remarkably, the selection of individual alleles for expression at the IGF2BP1 locus occurs during early stages of transcription elongation.

\section{Methods}

\section{ChIP-chip analyses}

The amplification and preparation of immunoprecipitated DNA derived from HBL100 cells for hybridization to ENCODE arrays (Roche NimbleGen Inc., Madison, WI, USA) was performed essentially as described previously [53]. Sample labeling and array hybridization were performed at NimbleGen Systems Inc. Genomic control DNA was labeled with Cy3, and sample DNA was labeled with Cy5. Both Cy3- and Cy5-labeled DNA were hybridized to high-density arrays tiling through ENCODE regions with 50-mer oligonucleotides across nonrepetitive genomic regions. The ratios of the Cy3 and Cy5 intensities of each probe were calculated using NimbleGen Systems' proprietary software.

\section{Peak detection and false-positive rate calculation}

A genomic sequence was considered a possible CTCFbinding site if there were at least four probes among the sequence probe and the flanking probes within a window covering $250 \mathrm{bp}$ on both sides of the probe had $\log _{2}$ ratio values above a specified cutoff value. The cutoff value was calculated separately for each chromosome. The cutoff value is a given percentage of the value (mean $+6 \times$ standard deviation) of the $\log _{2}$ ratio values of all the probes covering the chromosome. The possible binding sites thus detected are called peaks. To calculate the false-positive rate (FPR) by data permutation, the $\log _{2}$ ratio values among probes were scrambled to generate a randomized data set for each individual chromosome. Multiple repetitions of this process generated 20 randomized data sets for each chromosome. Subsequently, the peak detection algorithm described above was applied to count the average number of peaks in the 20 randomized data sets using the same cutoff. The ratio of that number to the number of peaks from the nonrandomized data set is the FPR. The FPR is associated with the threshold setting, which is indicated by the value of cutoff $P$. Peak detection and randomization of data sets were repeated for different threshold settings of $P$. The corresponding FPRs were calculated and assigned to peaks. The FPR value assigned to the individual peaks is the value associated with the cutoff $P$ at which the peak is first detected.

Peak discovery was performed using chromatin immunoprecipitate:input ratios combined from adjacent oligonucleotides within 250-bp regions. The FPR of detection was estimated by permutation analyses in which the experimentally determined $\log _{2}$ ratio values were reassigned to probes in a random fashion, allowing selection of stringency and specificity levels. To define sites of CTCF interaction with high confidence, peaks were required to be present in all three biological replicates and to be generated at a FPR $<0.05$.

\section{Chromatin immunoprecipitation}

Chromatin was prepared for immunoprecipitation as described previously [54] by cross-linking the cells in $1 \%$ formaldehyde for 5 minutes and subjecting them to subsequent sonication until the bulk of DNA was 300 to $600 \mathrm{bp}$ in size. Chromatin corresponding to $2 \times 10^{7}$ cells was immunoprecipitated with anti-CTCF antibody (D31H2; Cell Signaling Technology, Danvers, MA, USA), anti-H3K9me3 antibody (ab8898; Abcam, Cambridge, MA, USA), anti-trimethyl K4-histone H3 antibody (ab8580; Abcam), anti-trimethyl K27-histone H3 antibody (Millipore 07-449, Billerica MA, USA) or antiRNA polymerase II antibody (sc899; Santa Cruz Biotechnology, Santa Cruz, CA, USA). Immunoprecipitates were washed, the DNA protein cross-links were reversed and the recovered DNA was tested by performing conventional quantitative PCR as described previously [54]. RNA polymerase II ChIP experiments were performed 
using the Matrix ChIP protocol [55]. Sequences of primers specific for the gene loci under study as well as the reference primers are available upon request.

\section{RNA extraction and RT-PCR}

Synthesis of cDNA was carried out according to the manufacturer's instructions (Qiagen, Valencia, CA, USA) using $1 \mu \mathrm{g}$ of total RNA. For detection of premRNA, RNA preparations were pretreated with TURBO DNase I (Ambion/Applied Biosystems) as described in the manufacturer's protocol. RT was carried out at $37^{\circ} \mathrm{C}$ for one hour.

\section{Cell culture}

Cell lines were cultured in RPMI 1640 medium supplemented with 10\% FCS, $2 \mathrm{mM} \mathrm{L}$-glutamine and the antibiotics penicillin $(50 \mathrm{U} / \mathrm{mL})$ and streptomycin.

\section{Sodium bisulfite conversions}

gDNA was treated with sodium bisulfite using the EZ DNA Methylation Kit (Zymo Research, Orange, CA, USA) according to the manufacturer's instructions. PCR amplification of bisulfite-treated DNA was performed using ZymoTaq DNA Polymerase (Zymo Research Corporation, Irvine, CA, USA) and conversion-specific primers targeted to the IGF2BP1 CTCF region (forward primer: 5'-TATTTTTTAGTTGGGTTAAT-TGGTG-3', reverse primer: 5'-ATACTACCTCTCCTTCCAAA ATCTC-3'). The amplified products were purified by gel electrophoresis and sequenced. Each case was scored as methylated or unmethylated, and the percentage of methylation was calculated using BiQ Analyzer software [33].

\section{TaqMan allelic discrimination assays}

TaqMan allelic discrimination assays were performed according to the manufacturer's instructions with the following adjustments: cDNA from B lymphoblasts was preamplified for 14 cycles. PCR products were gel-purified and subsequently used as templates in the genotyping of samples. The specific primer sequences used are avaliable upon request.

\section{In vitro CTCF binding analysis using immobilized templates}

Crude nuclear extract was prepared from $1 \times 10^{9}$ Jurkat cells grown in growth media (RPMI 1640 with 10\% fetal bovine serum) according to methods described previously [56]. Biotinylated template DNA was generated by PCR amplification of the IGF2BP1 intronic region using a biotinylated/nonbiotinylated primer combination. The specific primer sequences are available upon request. For each binding reaction, $1 \mathrm{pM}$ biotinylated DNA template was coupled to $50-\mu$ g streptavidin-linked magnetic beads (Dynabeads M-280 Streptavidin; Invitrogen, Carlsbad, CA, USA). Templates immobilized to magnetic beads were washed three times in B\&W buffer (5 mM Tris, pH 7.5, $0.5 \mathrm{mM}$ ethylenediaminetetraacetic acid (EDTA), $1 \mathrm{M} \mathrm{NaCl}$ ) and resuspended in Jurkat nuclear extract. After a two-hour incubation at $4{ }^{\circ} \mathrm{C}$, immobilized templates were washed three times in Dignam buffer D (20 mM 4-(2-hydroxyethyl)-1-piperazineethanesulfonic acid, pH 7.9, 20\% glycerol, $0.1 \mathrm{M} \mathrm{KCl}$, $1 \mathrm{mM}$ EDTA, $0.1 \mathrm{mM}$ ethylene glycol tetraacetic acid, $1 \%$ Nonidet P-40, $1 \mathrm{mM}$ dithiothreitol) containing protease inhibitor (P8340; Sigma, St Louis, MO, USA). To recover template-bound proteins, beads were incubated in elution buffer (5 mM Tris, pH 7.5, 0.5 mM EDTA, 1 $\mathrm{M} \mathrm{NaHCO}$ ) including protease inhibitors. After a 5minute incubation, the eluate was removed and transferred into a fresh tube. The presence of CTCF in the eluate was determined using standard Western blot analysis protocols.

\section{Additional material}

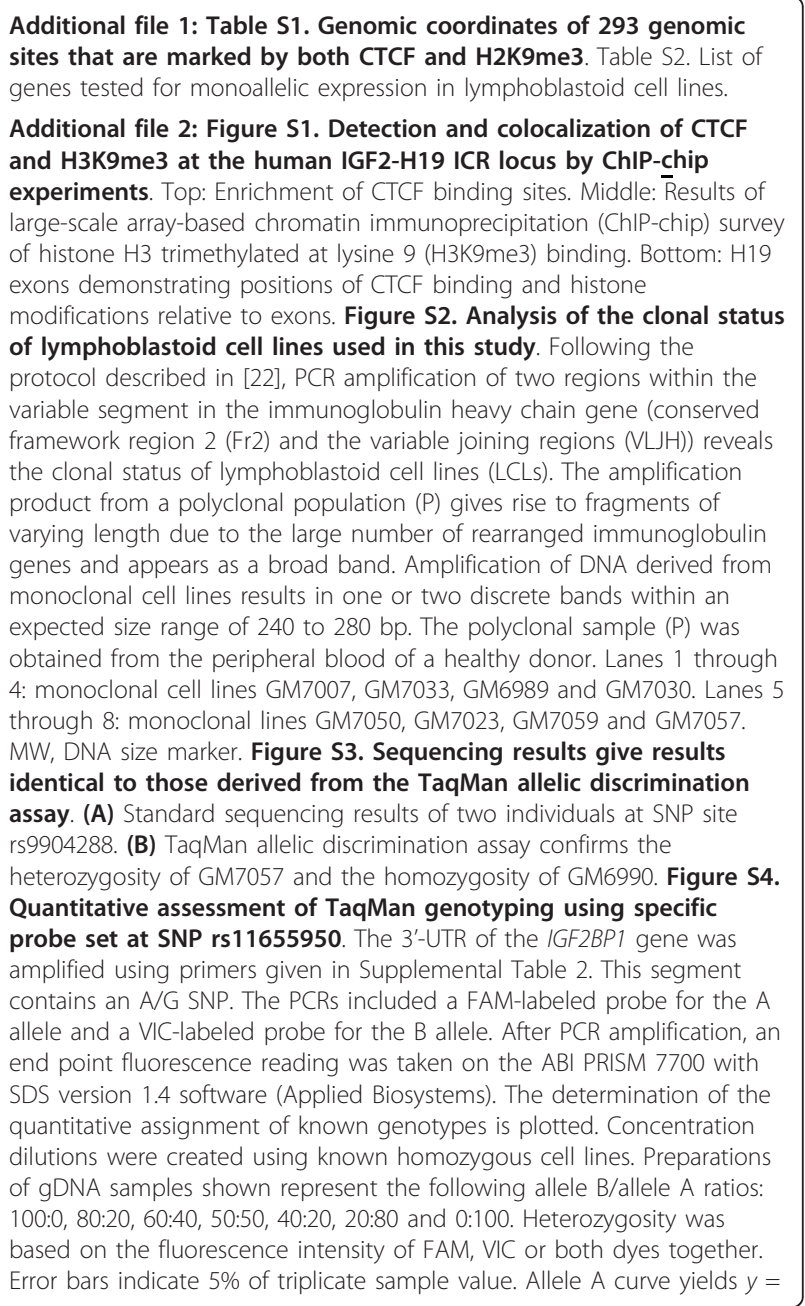
sites that are marked by both CTCF and H2K9me3. Table S2. List of genes tested for monoallelic expression in lymphoblastoid cell lines.

Additional file 2: Figure S1. Detection and colocalization of CTCF experiments. Top: Enrichment of CTCF binding sites. Middle: $\bar{R}$ esults of large-scale array-based chromatin immunoprecipitation (ChIP-chip) survey of histone $\mathrm{H} 3$ trimethylated at lysine 9 (H3K9me3) binding. Bottom: H19 exons demonstrating positions of CTCF binding and histone of lymphoblastoid cell lines used in this study. Following the protocol described in [22], PCR amplification of two regions within the variable segment in the immunoglobulin heavy chain gene (conserved framework region 2 (Fr2) and the variable joining regions $(\mathrm{VLJH})$ ) reveals the clonal status of lymphoblastoid cell lines (LCLs). The amplification product from a polyclonal population (P) gives rise to fragments of varying length due to the large number of rearranged immunoglobulin genes and appears as a broad band. Amplification of DNA derived from (x) discrete bands within an obtained from the peripheral blood of a healthy donor. Lanes 1 through 4: monoclonal cell lines GM7007, GM7033, GM6989 and GM7030. Lanes 5 through 8: monoclonal lines GM7050, GM7023, GM7059 and GM7057. MW, DNA size marker. Figure S3. Sequencing results give results identical to those derived from the TaqMan allelic discrimination assay. (A) Standard sequencing results of two individuals at SNP site rs9904288. (B) TaqMan allelic discrimination assay confirms the Quantitative assessment of TaqMan genotyping using specific probe set at SNP rs11655950. The 3'-UTR of the IGF2BP1 gene was amplified using primers given in Supplemental Table 2. This segment contains an A/G SNP. The PCRs included a FAM-labeled probe for the A allele and a VIC-labeled probe for the B allele. After PCR amplification, an SDS version 1.4 software (Applied Biosystems). The determination of the quantitative assignment of known genotypes is plotted. Concentration were created using known homozygous cell lines. Preparations 100:0, 80:20, 60:40, 50:50, 40:20, 20:80 and 0:100. Heterozygosity was Error bars indicate $5 \%$ of triplicate sample value. Allele A curve yields $y=$ 
$0.0102 x+0.0415$ with $R^{2}=0.98934$. Allele $B$ curve yields $y=-0.0085 x+$ 0.9796 with $R^{2}=0.98196$. Figure S5. Phylogenetic tree of motifs determined from motif analysis of the 8,462 loci derived from the ChIP-chip analysis using STAMP. All members of the highlighted group have matches identical to the canonical CTCF motif model as part of the JASPAR transcription factor binding site database. The resulting familial binding profile for all 68 such models is displayed. Figure S6. Fine mapping of CTCF motifs in sequences enriched in ChIP-chip experiments. Motif reads were mapped onto the genomic loci defined by ChIP-chip for CTCF binding. The extent of the ChIP-enriched sequences is indicated by red bar. Several read clusters are apparent and vary in depth and spatial extent (green areas). Figure S7. Frequency distribution of cluster depth for all motif clusters. A power law is apparent for clusters of depth $\leq 10$ with evident deviation in the population and a maximum of about 40 . The vertical green line demarcates the low and high confidence clusters. Figure S8.

Discrimination between high- and low-confidence sites. The region shown in Supplemental Figure S6 is annotated by overlaying enriched sequences with high- and low-confidence tracks. Figure S9. Sequences of immobilized templates used in in vitro binding experiments. CTCF core motifs $Y$ and $Z$ are underlined. Site-specific mutations in either the $Y$ or $Z$ motif are highlighted in yellow. In $Y^{\text {mut }} c h F l l$ and $Y^{m u t} m m R 3$, site-specific mutations (highlighted in green) were introduced to generate CTCF motifs identical to the chicken HS4 FII site and the mouse imprinting control region R3. The IGF2 wild-type huB1 sequence is derived from the human IGF2 imprinting control region containing the methylation-sensitive CTCF binding site B1.

\section{Abbreviations}

FCS: fetal calf serum; PCR: polymerase chain reaction; RT: reverse transcriptase; SNP: single-nucleotide polymorphism.

\section{Acknowledgements}

We thank Carol Ware, Angel Nelson, Jennifer Hesson and Chris Cavanaugh at the Institute for Stem Cell and Regenerative Medicine for providing us with the stem cells used in this study. This work was supported by grants from the National Institutes of Health (National Cancer Institute grant CA109597), the US Department of Defense (grant W81XWH-08-1-0636) and the John H. Tietze Foundation (to AK) and by a Mary Gates Endowment scholarship (to BJT).

\section{Author details}

${ }^{1}$ Institute for Stem Cell and Regenerative Medicine, University of Washington School of Medicine, 815 Mercer St., Seattle, WA 98109, USA. ${ }^{2}$ Department of Genome Sciences, University of Washington, $372015^{\text {th }}$ Ave NE, Seattle, WA 98195, USA. ${ }^{3}$ National Centre for Biomedical Engineering Science, National University of Ireland, Galway, University Road, Galway, Republic of Ireland. ${ }^{4}$ Department of Medicine (Endocrinology), Albert Einstein College of Medicine, 1300 Morris Park Ave, Bronx, NY 10461, USA. ${ }^{5}$ UW Medicine, South Lake Union, University of Washington School of Medicine, 815 Mercer St., Seattle, WA 98109, USA. ${ }^{6}$ Division of Medical Genetics, Department of Medicine, University of Washington, 1705 NE Pacific St., Seattle, WA 98195, USA. ${ }^{7}$ Department of Genetics, Albert Einstein College of Medicine, 1300 Morris Park Ave, Bronx, NY 10461, USA. ${ }^{8}$ Department of Medicine (Hematology), Albert Einstein College of Medicine, 1300 Morris Park Ave, Bronx, NY 10461, USA. ${ }^{9}$ Department of Radiation Oncology, University of Washington, 1959 NE Pacific St., Seattle, WA 98195, USA.

\section{Authors' contributions}

AK conceived of and designed the study. BJT, EDR and AK performed the experiments. PÓB, AAG, JMG and NK provided bioinformatics support and carried out the statistical analyses. PW and KB contributed the samples. BJT, PW, AAG and AK drafted the paper. All authors read and approved the final manuscript.

\section{Competing interests}

The authors declare that they have no competing interests.
Received: 25 February 2011 Accepted: 3 August 2011

Published: 3 August 2011

\section{References}

1. Delaval K, Feil R: Epigenetic regulation of mammalian genomic imprinting. Curr Opin Genet Dev 2004, 14:188-195.

2. Ferguson-Smith AC, Surani MA: Imprinting and the epigenetic asymmetry between parental genomes. Science 2001, 293:1086-1089.

3. Gregg C, Zhang J, Weissbourd B, Luo S, Schroth GP, Haig D, Dulac C: Highresolution analysis of parent-of-origin allelic expression in the mouse brain. Science 2010, 329:643-648.

4. Chess A, Simon I, Cedar H, Axel R: Allelic inactivation regulates olfactory receptor gene expression. Cell 1994, 78:823-834

5. Bix M, Locksley RM: Independent and epigenetic regulation of the interleukin-4 alleles in CD4 ${ }^{+}$T cells. Science 1998, 281:1352-1354.

6. Holländer GA, Zuklys S, Morel C, Mizoguchi E, Mobisson K, Simpson S, Terhorst C, Wishart W, Golan DE, Bhan AK, Burakoff SJ: Monoallelic expression of the interleukin-2 locus. Science 1998, 279:2118-2121.

7. Gimelbrant A, Hutchinson JN, Thompson BR, Chess A: Widespread monoallelic expression on human autosomes. Science 2007, 318:1136-1140.

8. Reik W, Walter J: Genomic imprinting: parental influence on the genome. Nat Rev Genet 2001, 2:21-32.

9. Bell AC, Felsenfeld G: Methylation of a CTCF-dependent boundary controls imprinted expression of the lgf2 gene. Nature 2000, 405:482-485.

10. Hark AT, Schoenherr CJ, Katz DJ, Ingram RS, Levorse JM, Tilghman SM: CTCF mediates methylation-sensitive enhancer-blocking activity at the $\mathrm{H19} /$ Igf2 locus. Nature 2000, 405:486-489.

11. Kanduri C, Pant V, Loukinov D, Pugacheva E, Qi CF, Wolffe A, Ohlsson R, Lobanenkov W: Functional association of CTCF with the insulator upstream of the $\mathrm{H} 19$ gene is parent of origin-specific and methylationsensitive. Curr Biol 2000, 10:853-856.

12. Phillips JE, Corces VG: CTCF: master weaver of the genome. Cell 2009, 137:1194-1211.

13. Parelho V, Hadjur S, Spivakov M, Leleu M, Sauer S, Gregson HC, Jarmuz A, Canzonetta C, Webster Z, Nesterova T, Cobb BS, Yokomori K, Dillon N, Aragon L, Fisher AG, Merkenschlager M: Cohesins functionally associate with CTCF on mammalian chromosome arms. Cell 2008, 132:422-433.

14. Rubio ED, Reiss DJ, Welcsh PL, Disteche CM, Filippova GN, Baliga NS, Aebersold R, Ranish JA, Krumm A: CTCF physically links cohesin to chromatin. Proc Natl Acad Sci USA 2008, 105:8309-8314.

15. Stedman W, Kang H, Lin S, Kissil JL, Bartolomei MS, Lieberman PM: Cohesins localize with CTCF at the KSHV latency control region and at cellular c-myc and H19/lgf2 insulators. EMBO J 2008, 27:654-666.

16. Wendt KS, Yoshida K, Itoh T, Bando M, Koch B, Schirghuber E, Tsutsumi S, Nagae G, Ishihara K, Mishiro T, Yahata K, Imamoto F, Aburatani H, Nakao M, Imamoto N, Maeshima K, Shirahige K, Peters JM: Cohesin mediates transcriptional insulation by CCCTC-binding factor. Nature 2008, 451:796-801.

17. Hadjur S, Williams LM, Ryan NK, Cobb BS, Sexton T, Fraser P, Fisher AG, Merkenschlager M: Cohesins form chromosomal cis-interactions at the developmentally regulated IFNG locus. Nature 2009, 460:410-413.

18. Hou C, Dale R, Dean A: Cell type specificity of chromatin organization mediated by CTCF and cohesin. Proc Natl Acad Sci USA 2010, 107:3651-3656.

19. Nativio R, Wendt KS, Ito $Y$, Huddleston JE, Uribe-Lewis S, Woodfine K, Krueger C, Reik W, Peters JM, Murrell A: Cohesin is required for higherorder chromatin conformation at the imprinted IGF2-H19 locus. PLOS Genet 2009, 5:e1000739.

20. Kacem S, Feil R: Chromatin mechanisms in genomic imprinting. Mamm Genome 2009, 20:544-556.

21. Wen $B$, Wu H, Bjornsson H, Green RD, Irizarry R, Feinberg AP: Overlapping euchromatin/heterochromatin-associated marks are enriched in imprinted gene regions and predict allele-specific modification. Genome Res 2008, 18:1806-1813.

22. Diss TC, Pan L, Peng H, Wotherspoon AC, Isaacson PG: Sources of DNA for detecting B cell monoclonality using PCR. J Clin Pathol 1994, 47:493-496.

23. Nielsen J, Christiansen J, Lykke-Andersen J, Johnsen AH, Wewer UM, Nielsen FC: A family of insulin-like growth factor II mRNA-binding proteins represses translation in late development. Mol Cell Biol 1999, 19:1262-1270. 
24. Noubissi FK, Elcheva I, Bhatia N, Shakoori A, Ougolkov A, Liu J, Minamoto T, Ross J, Fuchs SY, Spiegelman VS: CRD-BP mediates stabilization of $\beta \operatorname{TrCP1}$ and c-myc mRNA in response to $\beta$-catenin signalling. Nature 2006, 441:898-901.

25. Runge S, Nielsen FC, Nielsen J, Lykke-Andersen J, Wewer UM, Christiansen J: H19 RNA binds four molecules of insulin-like growth factor II mRNAbinding protein. J Biol Chem 2000, 275:29562-29569.

26. Engel $N$, Thorvaldsen $\lrcorner$, Bartolomei MS: CTCF binding sites promote transcription initiation and prevent DNA methylation on the maternal allele at the imprinted H19/lgf2 locus. Hum Mol Genet 2006, 15:2945-2954.

27. Mahony S, Hendrix D, Golden A, Smith TJ, Rokhsar DS: Transcription factor binding site identification using the self-organizing map. Bioinformatics 2005, 21:1807-1814.

28. Mahony S, Benos PV: STAMP: a web tool for exploring DNA-binding motif similarities. Nucleic Acids Res 2007, , 35 Web server: W253-W258.

29. Sandelin A, Alkema W, Engström P, Wasserman WW, Lenhard B: JASPAR: an open-access database for eukaryotic transcription factor binding profiles. Nucleic Acids Res 2004, 32 Database: D91-D94.

30. Kim TH, Abdullaev ZK, Smith AD, Ching KA, Loukinov DI, Green RD, Zhang $M Q$, Lobanenkov $W$, Ren B: Analysis of the vertebrate insulator protein CTCF-binding sites in the human genome. Cell 2007, 128:1231-1245.

31. Zhang ZD, Rozowsky J, Snyder M, Chang J, Gerstein M: Modeling ChIP sequencing in silico with applications. PLOS Comput Biol 2008, 4:e1000158.

32. Gombert WM, Krumm A: Targeted deletion of multiple CTCF-binding elements in the human C-MYC gene reveals a requirement for CTCF in C-MYC expression. PLoS One 2009, 4:e6109.

33. Bock C, Reither S, Mikeska T, Paulsen M, Walter J, Lengauer T: BiQ Analyzer: visualization and quality control for DNA methylation data from bisulfite sequencing. Bioinformatics 2005, 21:4067-4068.

34. Guenther MG, Levine SS, Boyer LA, Jaenisch R, Young RA: A chromatin landmark and transcription initiation at most promoters in human cells. Cell 2007, 130:77-88.

35. Krumm A, Hickey LB, Groudine M: Promoter-proximal pausing of RNA polymerase II defines a general rate-limiting step after transcription initiation. Genes Dev 1995, 9:559-572.

36. O'Brien T, Lis JT: RNA polymerase II pauses at the $5^{\prime}$ end of the transcriptionally induced Drosophila hsp70 gene. Mol Cell Biol 1991, 11:5285-5290

37. Zeitlinger J, Stark A, Kellis M, Hong JW, Nechaev S, Adelman K, Levine M, Young RA: RNA polymerase stalling at developmental control genes in the Drosophila melanogaster embryo. Nat Genet 2007, 39:1512-1516.

38. Heintzman ND, Hon GC, Hawkins RD, Kheradpour P, Stark A, Harp LF, Ye Z, Lee LK, Stuart RK, Ching CW, Ching KA, Antosiewicz-Bourget JE, Liu H, Zhang X, Green RD, Lobanenkov W, Stewart R, Thomson JA, Crawford GE, Kellis M, Ren B: Histone modifications at human enhancers reflect global cell-type-specific gene expression. Nature 2009, 459:108-112.

39. Mikkelsen TS, Xu Z, Zhang X, Wang L, Gimble JM, Lander ES, Rosen ED: Comparative epigenomic analysis of murine and human adipogenesis. Cell 2010, 143:156-169.

40. Renda M, Baglivo I, Burgess-Beusse B, Esposito S, Fattorusso R, Felsenfeld G, Pedone PV: Critical DNA binding interactions of the insulator protein CTCF: a small number of zinc fingers mediate strong binding, and a single finger-DNA interaction controls binding at imprinted loci. J Biol Chem 2007, 282:33336-33345.

41. Kadota M, Yang HH, Hu N, Wang C, Hu Y, Taylor PR, Buetow KH, Lee MP: Allele-specific chromatin immunoprecipitation studies show genetic influence on chromatin state in human genome. PLoS Genet 2007, 3:e81.

42. Kerkel K, Spadola A, Yuan E, Kosek J, Jiang L, Hod E, Li K, Murty W, Schupf N, Vilain E, Morris M, Haghighi F, Tycko B: Genomic surveys by methylation-sensitive SNP analysis identify sequence-dependent allelespecific DNA methylation. Nat Genet 2008, 40:904-908.

43. Knight JC, Keating BJ, Rockett KA, Kwiatkowski DP: In vivo characterization of regulatory polymorphisms by allele-specific quantification of RNA polymerase loading. Nat Genet 2003, 33:469-475.

44. Maynard ND, Chen J, Stuart RK, Fan JB, Ren B: Genome-wide mapping of allele-specific protein-DNA interactions in human cells. Nat Methods 2008, 5:307-309.

45. McCann JA, Muro EM, Palmer C, Palidwor G, Porter CJ, AndradeNavarro MA, Rudnicki MA: ChIP on SNP-chip for genome-wide analysis of human histone H4 hyperacetylation. BMC Genomics 2007, 8:322.
46. Delaval K, Govin J, Cerqueira F, Rousseaux S, Khochbin S, Feil R: Differential histone modifications mark mouse imprinting control regions during spermatogenesis. EMBO J 2007, 26:720-729.

47. Fournier C, Goto Y, Ballestar E, Delaval K, Hever AM, Esteller M, Feil R: Allelespecific histone lysine methylation marks regulatory regions at imprinted mouse genes. EMBO J 2002, 21:6560-6570.

48. Mikkelsen TS, Ku M, Jaffe DB, Issac B, Lieberman E, Giannoukos G, Alvarez P, Brockman W, Kim TK, Koche RP, Lee W, Mendenhall E, O'Donovan A, Presser A, Russ C, Xie X, Meissner A, Wernig M, Jaenisch R, Nusbaum C, Lander ES, Bernstein BE: Genome-wide maps of chromatin state in pluripotent and lineage-committed cells. Nature 2007, 448:553-560.

49. Ioannidis P, Kottaridi C, Dimitriadis E, Courtis N, Mahaira L, Talieri M, Giannopoulos A, lliadis K, Papaioannou D, Nasioulas G, Trangas T: Expression of the RNA-binding protein CRD-BP in brain and non-small cell lung tumors. Cancer Lett 2004, 209:245-250.

50. loannidis P, Mahaira L, Papadopoulou A, Teixeira MR, Heim S, Andersen JA, Evangelou E, Dafni U, Pandis N, Trangas T: CRD-BP: a c-Myc mRNA stabilizing protein with an oncofetal pattern of expression. Anticancer Res 2003, 23:2179-2183.

51. loannidis P, Mahaira L, Papadopoulou A, Teixeira MR, Heim S, Andersen JA Evangelou E, Dafni U, Pandis N, Trangas T: 8q24 copy number gains and expression of the c-myc mRNA stabilizing protein CRD-BP in primary breast carcinomas. Int J Cancer 2003, 104:54-59.

52. Ioannidis P, Trangas T, Dimitriadis E, Samiotaki M, Kyriazoglou I, Tsiapalis CM, Kittas C, Agnantis N, Nielsen FC, Nielsen J, Christiansen J, Pandis N: C-MYC and IGF-II mRNA-binding protein (CRD-BP/IMP-1) in benign and malignant mesenchymal tumors. Int J Cancer 2001, 94:480-484.

53. Bieda $M, X u X$, Singer $M A$, Green $R$, Farnham PJ: Unbiased location analysis of E2F1-binding sites suggests a widespread role for E2F1 in the human genome. Genome Res 2006, 16:595-605.

54. Gombert WM, Farris SD, Rubio ED, Morey-Rosler KM, Schubach WH, Krumm A: The c-myc insulator element and matrix attachment regions define the c-myc chromosomal domain. Mol Cell Biol 2003, 23:9338-9348.

55. Flanagin S, Nelson JD, Castner DG, Denisenko O, Bomsztyk K: Microplatebased chromatin immunoprecipitation method, Matrix ChIP: a platform to study signaling of complex genomic events. Nucleic Acids Res 2008, 36: e17.

56. Dignam JD, Lebovitz RM, Roeder RG: Accurate transcription initiation by RNA polymerase II in a soluble extract from isolated mammalian nuclei. Nucleic Acids Res 1983, 11:1475-1489.

57. Chung JH, Bell AC, Felsenfeld G: Characterization of the chicken $\beta$-globin insulator. Proc Natl Acad Sci USA 1997, 94:575-580.

doi:10.1186/1756-8935-4-14

Cite this article as: Thomas et al:: Allele-specific transcriptional elongation regulates monoallelic expression of the IGF2BP1 gene. Epigenetics \& Chromatin 2011 4:14.

\section{Submit your next manuscript to BioMed Central and take full advantage of:}

- Convenient online submission

- Thorough peer review

- No space constraints or color figure charges

- Immediate publication on acceptance

- Inclusion in PubMed, CAS, Scopus and Google Scholar

- Research which is freely available for redistribution 